\title{
Long-term subjective cognitive functioning following adjuvant systemic treatment: 7-9 years follow-up of a nationwide cohort of women treated for primary breast cancer
}

\author{
A Amidi ${ }^{*},{ }^{1}$, S Christensen ${ }^{1}$, M Mehlsen ${ }^{1}$, A B Jensen ${ }^{2}$, A D Pedersen ${ }^{3}$ and R Zachariae ${ }^{1}$ \\ ${ }^{1}$ Unit for Psychooncology and Health Psychology, Aarhus University Hospital \& Aarhus University, Bartholins Allé 9, bygn. 1340, \\ DK-8000 Aarhus C, Denmark; ${ }^{2}$ Department of Oncology, Aarhus University Hospital, Nørrebrogade 44, DK-8000 Aarhus C, \\ Denmark and ${ }^{3}$ Vejlefjord Rehabilitation, Sanatorievej 27b, DK-7140 Stouby, Denmark
}

Background: There is growing concern among breast cancer $(\mathrm{BC})$ patients and survivors about cognitive impairment following systemic treatments. The aim of the present study was to investigate the long-term effects of standard systemic adjuvant therapies on subjective cognitive impairment (SCI) in a large nationwide cohort of BC survivors 7-9 years after primary surgery.

Methods: Participants were recruited from the nationwide Psychosocial Factors and Breast Cancer inception cohort of Danish women treated for primary BC. SCl was assessed with the Cognitive Failures Questionnaire and women allocated to systemic treatment according to nationwide standard protocols were compared with women who had not received any systemic treatments.

Results: A total of 1889 recurrence-free survivors were eligible for analysis. No difference in $\mathrm{SCl}$ was found between survivors across standardized systemic treatment protocols when analyses were stratified by menopausal status and adjusted for possible sociodemographic and treatment-related confounders. The frequency of significant $\mathrm{SCl}$ in a subgroup of survivors in the age range $65-74$ years was $\sim 7 \%$.

Conclusions: No differences in long-term SCl at 7-9 years post surgery were found between women who had received systemic therapies and those who had not. Furthermore, the observed proportion of survivors with significant $\mathrm{SCl}$ was comparable to normative data. These results are important to communicate to patients, survivors, and clinicians alike, especially in the light of increasing concern about cognitive impairment following systemic therapies.

There is growing concern among breast cancer (BC) patients and survivors regarding possible cognitive impairment following systemic treatments (Van Londen et al, 2014). Reports of subjective cognitive impairment (SCI) following cancer treatment are frequent among BC patients (Pullens et al, 2010; Ganz et al, 2013). In contrast, results from neuropsychological studies of impairment of cognitive functions have been inconsistent (Jenkins et al, 2006, 2008; Mehlsen et al, 2009; Yamada et al, 2010;
Koppelmans et al, 2013), and although SCI and neuropsychological outcomes are usually poorly correlated (Pullens et al, 2010; Hutchinson et al, 2012), understanding the course and causes of SCI is relevant due to its potential impact on survivors' quality of life and daily functioning (Boykoff et al, 2009; Reid-Arndt et al, 2010; Von Ah et al, 2012). A systematic review found SCI rates in BC populations to range from 20 to $90 \%$, but the available evidence regarding the association between SCI and systemic BC treatment 
was inconclusive (Pullens et al, 2010). The majority of studies included in the review included participants ranging from 0 to 5 years in time since treatment, and most studies were based on small samples $(N<100)$. Only little is known about the possible long-term effects ( +5 years) of systemic therapies on SCI in BC. A limitation of most of the existing studies has been their primary focus on chemotherapy (CT). Given the heterogeneity of BC treatment with the application of different treatment protocols and modalities, it remains unclear to what extent cognitive impairments may be caused by the CT itself, or by other treatment modalities (Pullens et al, 2010). For example, oestrogen receptorpositive patients usually receive endocrine therapy (ET) for a period of 5 years. Endocrine therapies suppress tumour growth by either reducing oestrogen levels, or by blocking oestrogen sensitive receptors (Buwalda and Schagen, 2013). Oestrogen receptors have been located in different brain regions (McEwen and Alves, 1999) and ET may thus have a direct effect on the brain. Studies in noncancer populations have observed an association between menopause transitioning women and cognitive functions (Weber et al, 2013). A recent study found that over $50 \%$ of BC survivors who were or had previously been treated with adjuvant ET were concerned about late-effects such as cognitive dysfunction (Van Londen et al, 2014). However, most studies investigating SCI in survivors receiving ET have focused on the short-term effects (Shilling and Jenkins, 2007; Ribi et al, 2012; Schilder et al, 2012; Kilickap et al, 2013; Ganz et al, 2014), and thus very little is currently known about the possible long-term impact of ET on SCI. Furthermore, the heterogeneity of BC treatment remains a methodological challenge, and due to inadequate statistical power in most studies, combined effects of adjuvant treatments $(\mathrm{CT}+\mathrm{ET})$ are generally poorly investigated (Buwalda and Schagen, 2013).

The aim of the present study was to investigate the long-term effects of standard systemic treatment protocols on SCI in a large nationwide cohort of BC survivors 7-9 years after primary treatment adjusted for potential confounders. We hypothesised that survivors allocated to treatment with CT, ET, or a combination of the two, would report higher levels of SCI compared with women who had not received adjuvant treatment. A secondary aim was to investigate the overall level of SCI in a subgroup of $\mathrm{BC}$ survivors for whom comparable normative data were available.

\section{MATERIALS AND METHODS}

Data sources. Participants were recruited from the nationwide Psychosocial Factors and Breast cancer (PFAB) inception cohort of 4917 Danish women treated surgically for primary BC between October 2001 and March 2004. The PFAB cohort was established in collaboration with the Danish Breast Cancer Cooperative Group (DBCG) and details concerning the cohort have previously been published (Christensen et al, 2009). Eligible women were informed about the study at the surgical departments, and the Charlson Comorbidity Index (Charlson et al, 1987) was completed for each patient.

Registry data. Addresses, Danish Civil Registration personal identification numbers, and data concerning eligibility, comorbidity, histopathology, and treatment-related variables were obtained directly from the surgical departments responsible for treating $\mathrm{BC}$ in Denmark during the inclusion period, as well as from the DBCG registry. All departments in Denmark involved in the treatment of $\mathrm{BC}$ patients systematically report information on diagnosis, treatment, and follow-up to the DBCG database and an estimated $97 \%$ of all eligible women having had surgery for primary BC in Denmark during the study period were identified (Rostgaard et al, 2000).
Pre-cancer data on demographic factors, psychiatric history, ethnicity and socioeconomic variables were obtained from the nationwide Danish longitudinal registries through a linkage serviced by Statistics Denmark (Thygesen et al, 2011). Data from the different sources were linked using the women's personal identification numbers, a 10 digit unique number, including date of birth, used by all public registration systems. Danish ethnicity was defined as Danish citizenship, having been born in Denmark, and at least one parent being a Danish citizen. Psychiatric history was defined as previous in- or outpatient psychiatric treatment recorded until 1-month pre-surgery. For the present study information on disease stage at time of cohort enrolment, subsequent recurrence and secondary cancers, and treatment protocol assignment was updated through a linkage to the DBCG database and the Danish Cancer Registry. The Danish Cancer Registry includes data on the incidence of cancer in the Danish population since 1943 (Gjerstorff, 2011).

Eligibility. Eligible patients were women between 18 and 70 years of age at time of surgery, Danish residents, with histologically confirmed BC T1-3, N0-3, and M0 according to the TNM (Tumour, Node, Metastasis) classification (Singletary et al, 2002) and no history of previous cancers, except non-melanoma skin cancer or carcinoma in situ of the cervix uteri. Other criteria were ability to read Danish and being capable of completing a questionnaire. In the present study, women $<35$ years of age $(N=33)$ at time of primary surgery were excluded because all women in this age group are allocated to systemic therapy. Based on updated information from DBCG and the Danish Cancer Registry, women with secondary cancer or recurrence were also excluded at the 7-9 year follow-up, as well as women who had not been treated according to a DBCG standard protocol or who had been treated according to protocols not corresponding to their menopausal status at the time of primary surgery.

Questionnaire cohort. All eligible women were informed about the study at the surgical departments and consecutively mailed a questionnaire package 3-4 months post surgery. A total of 3343 women $(68.0 \%)$ returned the questionnaire and constituted the questionnaire cohort. A second assessment was conducted at a 15-month follow-up (O'Connor et al, 2011), and finally between June and August 2011, a 7-9 year follow-up questionnaire package was mailed out to all members of the questionnaire cohort. Two reminders were sent after 3 and 6 weeks to those participants who had not yet returned the questionnaire package.

Systemic treatment protocols. During the study period, the DBCG standard protocols 2001A-E and 2004C for adjuvant therapy were effective. The different protocols (A-E) and related treatment details are presented in Table 1. For postmenopausal women in protocol C, sequential treatment with Exemestan together with Tamoxifen was introduced in DBCG protocol 2004C from June 2004. Some of the first women included from this protocol have therefore been treated with Tamoxifen for up to $\sim 3.5$ years before the initiation of Exemestane treatment (2.5 years).

Subjective cognitive impairment. SCI was assessed at the 7-9 year follow-up. The 25-item Cognitive Failures Questionnaire (CFQ) assesses self-reported cognitive slips and failures in daily activities during the past 6 months (Broadbent et al, 1982). Each item is rated from 0 to 4 with the total score calculated as the sum of all items ranging from 0 to 100 with higher scores indicating higher levels of cognitive failures. The CFQ has been shown to have good psychometric properties with evidence of criterion validity (Broadbent et al, 1982; Bridger et al, 2013). We also calculated scores for the three individual CFQ factors as reported by Rast et al (2009): forgetfulness, distractibility, and false triggering. Cognitive Failure Questionnaire normative data were obtained from a 
Table 1. Systemic treatment protocols (A-E) grouped by menopausal status

\begin{tabular}{|c|c|c|c|}
\hline Group & Protocol & Treatment & Details \\
\hline \multirow[t]{3}{*}{ Premenopausal $(N=751)$} & A & & No adjuvant treatment \\
\hline & B & $\mathrm{CT}+\mathrm{ET}$ & 7 cycles of CEF + tamoxifen $(20 \mathrm{mg})^{\text {a }}$ \\
\hline & $\mathrm{D}$ & CT & 7 cycles of CEF \\
\hline \multirow[t]{3}{*}{ Postmenopausal $(N=1138)$} & A & & No adjuvant treatment \\
\hline & C & ET & Tamoxifen $(20 \mathrm{mg})+$ exemestane $(25 \mathrm{mg})^{\mathbf{b}}$ \\
\hline & $E$ & CT & 7 cycles of CMF \\
\hline \multicolumn{4}{|c|}{ 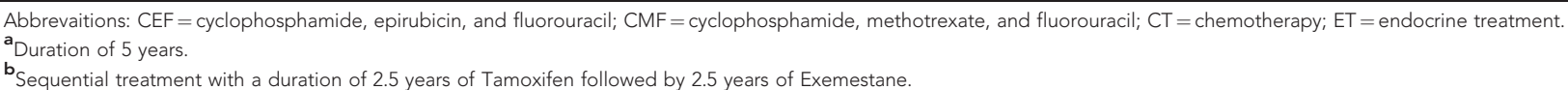 } \\
\hline
\end{tabular}

geriatric population (range: 64-73 years) from New Zealand (Knight et al, 2004).

Ethical approval. The study was approved by The Regional Science-Ethical Committees and The Danish Data Protection Agency.

Statistical Analysis. Differences in sociodemographic and clinical variables were tested with $\chi^{2}$-tests for categorical variables and univariate ANOVAs for continuous measures. CFQ total scores were calculated for all women with an item response rate $\geqslant 50 \%$ using mean substitution of missing items.

ANOVAs were conducted to assess the unadjusted associations between the treatment protocols and CFQ total and factor scores in the total sample. Using ANCOVA, the comparisons were repeated with stratification by menopausal status and adjustment for sociodemographic (age, education, ethnicity, marital status, parental status, personal income, household wealth, occupational status, comorbidity, and psychiatric status), and clinical (time since surgery, type of surgery, and radiotherapy status) covariates. Because sociodemographic factors have been found to be associated with advanced disease progression (i.e., tumour stage) at the time of diagnosis (Dalton et al, 2006), it is important to adjust for these factors, as they may potentially confound the relationship between systemic treatments and SCI. We hypothesised (planned contrast) that survivors from protocol A (no adjuvant treatment) would score lower on the CFQ compared with survivors from protocols B-E, which included CT, ET, or both. The stratification by menopausal status was necessary in order to eliminate the possible confounding effect of age. This approach was chosen because menopausal status at the time of diagnosis (and thereby indirectly age) partly determined protocol allocation with a higher proportion of premenopausal patients receiving CT, and because a statistically significant negative association was observed between age and CFQ score. In addition, menopause may itself be related to the experience of cognitive issues (Sullivan Mitchell and Fugate Woods, 2001). Thus for the premenopausal group, protocol A (no adjuvant treatment) was contrasted with protocol D $(\mathrm{CT})$ and $\mathrm{B}(\mathrm{CT}+\mathrm{ET})$, while in the postmenopausal group, protocol A (no adjuvant treatment) was contrasted with protocol E (CT) and C (ET).

To test whether the overall level of SCI was higher than could be expected, we compared the CFQ mean score from a normative population ranging between 63 and 74 years in age with BC survivors in the corresponding age range with a one-sample $t$-test. In addition, the proportion of survivors with significant SCI was determined as the frequency of survivors with a CFQ total scores exceeding 1 s.d. above the mean of the normative population. This criteria for significant SCI has been used in a previous study (Ganz et al, 2013).

The STROBE guidelines for reporting epidemiological studies were followed (Vandenbroucke et al, 2014). All statistical analyses were performed using SPSS version 19.0.0.1 (IBM SPSS Inc., Chicago, IL, USA).

\section{RESULTS}

A total of 1889 long-term BC survivors were considered eligible for analysis (see Figure 1). Mean substitution of missing CFQ items were performed for 66 (3\%) women. Mean overall age was 63.3 years (s.d. $=8.2$; median $=64.0$; range $=43.3-79.7$ years $)$ with an average of 8.4 years since initial surgery (range: $7.2-9.8$ years). The majority were of Danish ethnicity (97\%), had an upper secondary education or higher $(71 \%)$, were occupationally engaged $(70 \%)$, and were either married or cohabiting (78\%) in the year prior to year of primary surgery. At the time of surgery, 39.8\% were premenopausal. At the time of the 7-9 year follow-up, a total of 777 women $(41.1 \%)$ had received CT consisting of either seven cycles of CEF, or seven cycles of CMF. Adjuvant ET had been administered to a total of $1234(65.3 \%)$ women and consisted of either 5 years of treatment with Tamoxifen $(20 \mathrm{mg})$ for premenopausal women, or a combination of 2.5 years of treatment with Tamoxifen $(20 \mathrm{mg})$ followed by 2.5 years of treatment with Exemestane $(25 \mathrm{mg})$ for postmenopausal women. Demographic, socioeconomic, and clinical variables for the pre- and postmenopausal women are presented in Table 2. In the premenopausal group, differences in demographic variables between participants allocated to different protocols were observed for age, time since surgery, and mean household net-wealth. No differences were observed in the postmenopausal group (see Table 2).

Protocol allocation did not differ between eligible postmenopausal participants and nonparticipants from the entire cohort $(N=3304)$ at $7-9$ year follow-up, but a higher proportion of participants in the premenopausal group were allocated to protocol D compared with nonparticipants, $\left(\chi^{2}(2)=6.4, P=0.04\right.$, data not shown). The attrition rate from 3 months to 7-9 years follow-up was low (9.6\%), and there was no statistically significant difference between non-responders and responders at the 7-9 year follow-up regarding treatment protocol allocation when stratified by menopausal status (premenopausal, $P=0.99$; postmenopausal, $P=0.44$, data not shown).

Cognitive Failures Questionnaire. The CFQ revealed high interitem consistency (Cronbach's alpha $=0.92$ ) in the current sample. The distribution of the CFQ and other relevant covariates were formally tested and visually inspected with P-P plots and frequency histograms and appeared to be normally distributed. The mean total CFQ score for the entire sample was 31.4 (s.d.=12.7). A significant difference was observed between pre$(M=33.1$, s.d. $=13.5)$ and postmenopausal survivors $(M=30.3$, s.d. $=12.0 ; t(1887)=4.7, P<0.001)$. CFQ was negatively associated with age $(r=-0.13, P<0.001)$. 


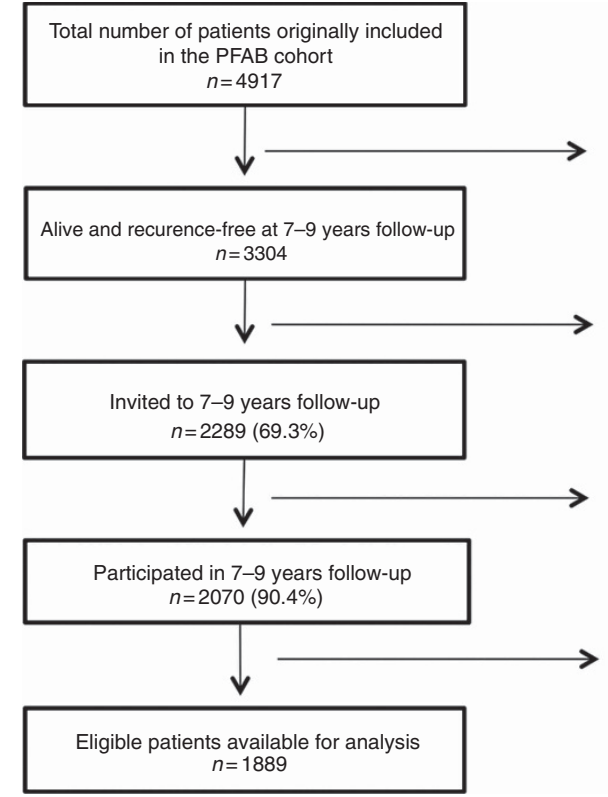

Figure 1. Flowchart of selection of patients.

CFQ and treatment protocols. Unadjusted and unstratified comparisons of the treatment protocols initially revealed a significant difference $(\mathrm{F}(11884)=5.66, P<0.001)$ with women from protocols $\mathrm{B}$ and $\mathrm{D}$ (both including treatment with CEF CT) scoring higher on CFQ total compared with women from protocol A (no adjuvant treatment; both $P<0.05$ ). These results were consistent for all CFQ factor scores (all $P<0.01$ ). To eliminate potential confounding by age, subsequent planned comparisons were stratified by menopausal status and adjusted for other potentially confounding sociodemographic and treatment -related variables. These analyses revealed no differences in SCI between women allocated to protocol A, and those allocated to protocol B or D in the premenopausal group. Similarly, in the postmenopausal group, women allocated to protocol A did not significantly differ from women allocated to protocol $\mathrm{C}$ or E. Furthermore, no differences were found for any of the individual CFQ factor scores. All unadjusted and adjusted analyses of CFQ total and factor scores are presented in Table 3.

CFQ and normative data. Knight et al (2004) reported a mean CFQ total score of 31.2 (s.d. = 11.2) for a healthy normative group $(N=161)$ in the age range of 65-74 years. In the present study, women in the corresponding age range $(65-74$ years, $n=680)$ reported a CFQ mean of 29.62 (s.d.=11.1), which is not statistically different from the normative sample mean $(t(839)=1.62, P=0.11)$. Using the normative data above and the criteria described in the Materials and Methods section, a CFQ total score above 42.4 was considered to indicate significant SCI. In total, $7.3 \%$ of $\mathrm{BC}$ survivors in the corresponding age range exceeded this cutoff score and were accordingly classified as experiencing significant SCI.

\section{DISCUSSION}

The primary aim of the present study was to investigate possible long-term effects of systemic treatments on SCI in BC survivors allocated to standard treatment protocols. We hypothesised that women allocated to protocols that included adjuvant medical treatments would report higher levels of SCI compared with those who had not received adjuvant treatment. Initially, this hypothesis was confirmed in the unstratified analyses. However, when the

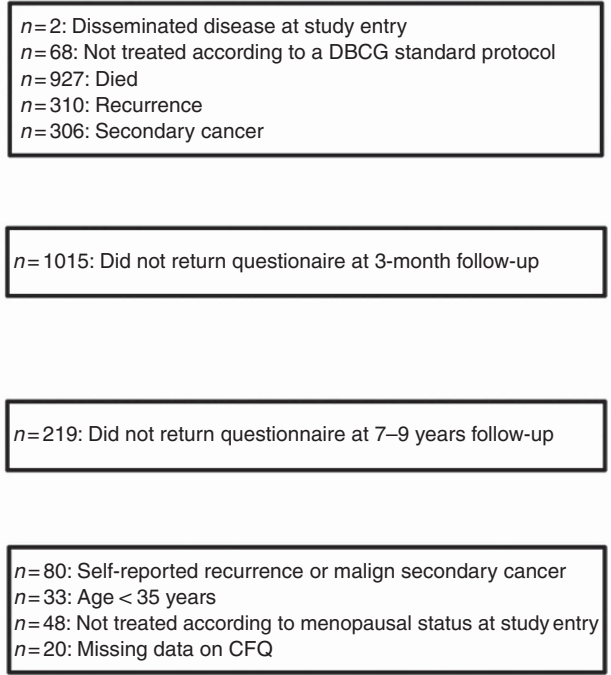

necessary stratification by menopausal status due to the potential confounding effect of age was applied, the results failed to support the hypothesis. Hence adjuvant treatments according to standard protocols were not found to be associated with long-term SCI. These findings provide new insights regarding the long-term association between systemic treatments and SCI. Although other studies have indicated an association between systemic treatments and SCI (Ribi et al, 2012; Deprez et al, 2014), most of these studies have investigated this relatively shortly after treatment completion. Our findings are consistent with another large long-term study by Ahn et al (2007), who did not detect a difference between BC survivors $(N=1933)$ receiving different, or combined adjuvant treatments, an average of 4 years after treatment. Limitations of their study, however, included considerable variability in time since surgery, which ranged from 1 to 12 years, and the measurement of SCI was restricted to two single items related to memory and concentration problems. In contrast, Bender et al (2006) found that 1 year after treatment, 57 survivors who had received both CT + ET $(N=19)$ reported higher levels of memory complaints, compared with those who had received surgery only $(N=19)$ or CT $(N=19)$. Due to the small sample size, these results should be interpreted with caution. Furthermore, between-study differences in time since surgery limit the comparability of the studies.

Although our results did not indicate any associations between systemic treatments and SCI, it is still important to evaluate the overall level of SCI, as this may differ from healthy population levels. Unfortunately, no established cutoff score is currently available for the CFQ, so we applied normative data published for a geriatric population (65-74 years) in New Zealand (Knight et al, 2004), which may serve as a reasonable comparison country, given the similarities between New Zealand and Denmark in size, educational level, and socioeconomic status (OECD Better Life Index, 2014). The mean CFQ total score in a subgroup of the Danish BC survivors in the corresponding age range (65-74 years) did not statistically differ from the mean of this normative population, suggesting that long-term BC survivors in this age range are not experiencing pronounced cognitive issues. Furthermore, using the normative data above, we determined the prevalence of women who reported significant SCI in this subgroup, which amounted to $7 \%$ of all survivors between 65 and 74 years of age. The proportion of women with significant SCI in this subgroup is lower than that observed in other studies in 
Table 2. Sociodemographic and clinical variables by menopausal status and standard treatment protocol for systemic therapy (A-E) ${ }^{a}$

Premenopausal survivors $(N=751)$

Postmenopausal survivors $(N=1138)$

\begin{tabular}{|c|c|c|c|c|c|c|c|c|}
\hline Protocol & $\mathrm{A}(-\mathrm{CT} /-\mathrm{ET})$ & $\mathrm{D}(\mathrm{CT})$ & $\mathrm{B}(\mathrm{CT}+\mathrm{ET})$ & $P$-value ${ }^{\mathrm{b}}$ & $\mathrm{A}(-\mathrm{CT} /-\mathrm{ET})$ & $E(C T)$ & $C(E T)$ & $P$-value ${ }^{b}$ \\
\hline$N(\%)$ & $139(18.5)$ & 104 (13.9) & $508(67.6)$ & & $247(21.7)$ & $165(14.5)$ & $726(63.8)$ & \\
\hline \multicolumn{9}{|l|}{ Sociodemographics, mean (s.d.) } \\
\hline Age (years) & $56.4(4.1)$ & $54.6(5.3)$ & $55.1(4.8)$ & 0.005 & $68.9(5.0)$ & $68.2(4.6)$ & $68.7(5.0)$ & 0.39 \\
\hline Time since surgery (years) & $8.3(0.68)$ & $8.5(0.69)$ & $8.5(0.68)$ & 0.015 & $8.4(0.70)$ & $8.5(0.64)$ & $8.4(0.67)$ & 0.64 \\
\hline Income (in 10000 US\$) & $5.2(3.1)$ & $4.6(1.7)$ & $4.7(2.0)$ & 0.08 & $3.7(2.0)$ & $3.7(2.1)$ & $3.6(2.0)$ & 0.62 \\
\hline Mean household wealth (in 10000 US\$) ${ }^{c}$ & $7.2(15.7)$ & $3.2(10.5)$ & $4.6(9.5)$ & 0.011 & $8.9(12.8)$ & $8.0(12.5)$ & $9.9(19.6)$ & 0.42 \\
\hline Ethnicity, N (\%) & & & & 0.33 & & & & 0.18 \\
\hline $\begin{array}{l}\text { Native } \\
\text { Immigrant or descendant }\end{array}$ & $\begin{aligned} 133 & (95.7) \\
6 & (4.3)\end{aligned}$ & $\begin{array}{c}102(98.1) \\
1(1.0)\end{array}$ & $\begin{array}{c}490(96.5) \\
17(3.3)\end{array}$ & & $\begin{array}{l}245(99.2) \\
2(0.8)\end{array}$ & $\begin{array}{c}161(97.6) \\
4(2.4)\end{array}$ & $\begin{array}{c}705(97.1) \\
21(2.9)\end{array}$ & \\
\hline Education, $N(\%)$ & & & & 0.34 & & & & 0.88 \\
\hline $\begin{array}{l}\text { Graduate degree ( } \geqslant 18 \text { years) } \\
<\text { Graduate degree }(14-17 \text { years) } \\
\text { Upper secondary ( } 11-13 \text { years) } \\
\text { Secondary (8-10 years) } \\
\text { Lower secondary ( } 7 \text { years) }\end{array}$ & $\begin{aligned} 12 & (8.6) \\
37 & (26.6) \\
66 & (47.5) \\
18 & (12.9) \\
5 & (3.6)\end{aligned}$ & $\begin{array}{c}11(10.6) \\
34(32.7) \\
35(33.7) \\
19(18.3) \\
4(3.8)\end{array}$ & $\begin{aligned} 31 & (6.1) \\
168 & (33.1) \\
201 & (39.6) \\
88 & (17.3) \\
15 & (3.0)\end{aligned}$ & & $\begin{array}{l}7(2.8) \\
51(20.6) \\
95(38.5) \\
34(13.8) \\
58(23.5)\end{array}$ & $\begin{array}{ll}7 & (4.2) \\
31 & (18.8) \\
72 & (43.6) \\
16 & (9.7) \\
37 & (22.4)\end{array}$ & \begin{tabular}{r|}
$24(3.3)$ \\
$148(20.4)$ \\
$297(40.9)$ \\
$76(10.5)$ \\
$173(23.8)$
\end{tabular} & \\
\hline Occupational status, $N(\%)$ & & & & 0.63 & & & & 0.45 \\
\hline $\begin{array}{l}\text { Employee-medium/upper level } \\
\text { Employee-basic level } \\
\text { Unemployed, recipient of benefits, etc. } \\
\text { Old age pension } \\
\text { Early retirement pension }\end{array}$ & $\begin{array}{c}61(43.9) \\
73(52.5) \\
4(2.9) \\
- \\
1(0.7)\end{array}$ & $\begin{array}{c}44(42.3) \\
52(50.0) \\
4(3.8) \\
- \\
3(2.9)\end{array}$ & $\begin{array}{l}215(42.3) \\
248(48.8) \\
28(5.5) \\
- \\
15(3.0)\end{array}$ & & $\begin{array}{l}56(22.7) \\
72(29.1) \\
70(28.3) \\
20(8.1) \\
29(11.7)\end{array}$ & $\begin{array}{c}36(21.8) \\
67(40.6) \\
36(21.8) \\
9(5.5) \\
17(10.3)\end{array}$ & \begin{tabular}{c|}
$147(20.2)$ \\
$263(36.2)$ \\
$192(26.4)$ \\
$51(7.0)$ \\
$73(10.1)$
\end{tabular} & \\
\hline Marital status, $N(\%)$ & & & & 0.23 & & & & 0.92 \\
\hline $\begin{array}{l}\text { Married/cohabiting } \\
\text { Divorced/not cohabiting }\end{array}$ & $\begin{array}{r}108(77.7) \\
31(22.3)\end{array}$ & $\begin{array}{l}89(85.6) \\
15(14.4)\end{array}$ & $\begin{array}{l}398(78.3) \\
110(21.7)\end{array}$ & & $\begin{array}{r}191(77.3) \\
56(22.7)\end{array}$ & $\begin{array}{r}129(78.2) \\
36(21.8)\end{array}$ & $\begin{array}{l}557(76.7) \\
169(23.3)\end{array}$ & \\
\hline Children, N (\%) & & & & 0.12 & & & & 0.11 \\
\hline $\begin{array}{l}\text { No } \\
\text { Yes }\end{array}$ & $\begin{array}{r}21(15.1) \\
118(84.9)\end{array}$ & $\begin{array}{cl}7 & (6.7) \\
97 & (93.3)\end{array}$ & $\begin{array}{r}67(13.2) \\
441(86.8)\end{array}$ & & $\begin{array}{r}31(12.6) \\
216(87.4)\end{array}$ & $\begin{array}{c}11(6.7) \\
154(93.3)\end{array}$ & $\begin{array}{c}65(9.0) \\
661(91.0)\end{array}$ & \\
\hline \multicolumn{9}{|l|}{ Clinical variables } \\
\hline Radiotherapy, N (\%) & & & & 0.002 & & & & $<0.001$ \\
\hline $\begin{array}{l}\text { No } \\
\text { Yes }\end{array}$ & $\begin{array}{l}42(30.2) \\
97(69.8)\end{array}$ & $\begin{array}{l}22(21.2) \\
82(78.8)\end{array}$ & $\begin{array}{r}86(16.9) \\
422(83.1)\end{array}$ & & $\begin{array}{r}79(32.0) \\
168(68.0)\end{array}$ & $\begin{array}{r}45(27.3) \\
120(72.7)\end{array}$ & $\begin{array}{l}115(15.8) \\
611(84.2)\end{array}$ & \\
\hline Receptor status, N (\%) & & & & $<0.001$ & & & & $<0.001$ \\
\hline $\begin{array}{l}\text { Estrogen positive } \\
\text { Estrogen negative }\end{array}$ & $\begin{aligned} 137 & (98.6) \\
2 & (1.4)\end{aligned}$ & $104(100)$ & $\begin{array}{c}505(99.4) \\
-\end{array}$ & & $\begin{aligned} 242 & (98.0) \\
5 & (2.0)\end{aligned}$ & $165(100)$ & $\begin{array}{c}724(99.7) \\
-\end{array}$ & \\
\hline Axillary status, $N(\%)$ & & & & $<0.001$ & & & & $<0.001$ \\
\hline $\begin{array}{l}\text { No lymph node involvement } \\
\text { Lymph node involvement }\end{array}$ & $\begin{array}{l}139(100) \\
-\end{array}$ & $\begin{array}{l}53(51.0) \\
51(49.0)\end{array}$ & $\begin{array}{l}196(38.6) \\
312(61.4)\end{array}$ & & $\begin{array}{c}247(100) \\
-\end{array}$ & $\begin{array}{l}99(60.0) \\
66(40.0)\end{array}$ & $\begin{array}{l}267(36.8) \\
459(63.2)\end{array}$ & \\
\hline Tumour grade, $N(\%)$ & & & & $<0.001$ & & & & $<0.001$ \\
\hline $\begin{array}{l}\text { Grade } 1 \\
\text { Grade } 2 \\
\text { Grade } 3 \\
\text { Non-ductal tumour } \\
\text { Missing }\end{array}$ & $\begin{array}{c}87(62.6) \\
- \\
- \\
49(35.3) \\
3(2.2)\end{array}$ & $\begin{aligned} & 1(1.0) \\
& 18(17.3) \\
& 71(68.3) \\
& 12(11.5) \\
& 2(1.9) \\
&\end{aligned}$ & $\begin{aligned} & 109(21.5) \\
& 241(47.4) \\
& 77(15.2) \\
& 76(15.0) \\
& 5(1.0) \\
&\end{aligned}$ & & $\begin{array}{l}159(64.4) \\
- \\
- \\
82(33.2) \\
6(2.4)\end{array}$ & $\begin{array}{c}6(3.6) \\
53(32.1) \\
76(46.1) \\
29(17.6) \\
1(0.6)\end{array}$ & $\begin{array}{r}160(22.0) \\
376(51.8) \\
81(11.2) \\
109(15.0) \\
-\end{array}$ & \\
\hline Surgery type, $N(\%)$ & & & & $<0.001$ & & & & $<0.001$ \\
\hline $\begin{array}{l}\text { Mastectomy } \\
\text { Lumpectomy }\end{array}$ & $\begin{array}{l}42(30.2) \\
97(69.8)\end{array}$ & $\begin{array}{l}51(49.0) \\
53(51.0)\end{array}$ & $\begin{array}{l}282(55.5) \\
226(44.5)\end{array}$ & & $\begin{array}{r}84(34.0) \\
163(66.0)\end{array}$ & $\begin{array}{l}91(55.2) \\
74(44.8)\end{array}$ & $\begin{array}{l}398(54.8) \\
328(45.2)\end{array}$ & \\
\hline Charlson comorbidity index, N (\%) & & & & 0.83 & & & & 0.29 \\
\hline $\begin{array}{l}\text { No comorbidity } \\
\text { Comorbidity }(\mathrm{CCl} \text { score } \geqslant 1)\end{array}$ & $\begin{array}{c}131(94.2) \\
8(5.8)\end{array}$ & $\begin{array}{c}99(95.2) \\
5(4.8)\end{array}$ & $\begin{array}{c}473(93.1) \\
32(6.3)\end{array}$ & & $\begin{array}{r}220(89.1) \\
26(10.5)\end{array}$ & $\begin{array}{c}153(92.7) \\
12(7.3)\end{array}$ & $\begin{array}{r}641(88.3) \\
83(11.4)\end{array}$ & \\
\hline \multicolumn{9}{|l|}{ Psychiatric history, $N(\%)$} \\
\hline $\begin{array}{l}\text { No psychiatric history } \\
\text { Psychiatric history }\end{array}$ & $\begin{array}{c}129(92.8) \\
10(7.2) \\
\end{array}$ & $\begin{array}{c}101(97.1) \\
3(2.9) \\
\end{array}$ & $\begin{array}{c}477(93.9) \\
31(6.1) \\
\end{array}$ & 0.34 & $\begin{array}{c}228(92.3) \\
19(7.7) \\
\end{array}$ & $\begin{array}{c}157 \text { (95.2) } \\
8(4.8) \\
\end{array}$ & $\begin{array}{r}683(94.1) \\
43(5.9) \\
\end{array}$ & 0.46 \\
\hline \multicolumn{9}{|c|}{ 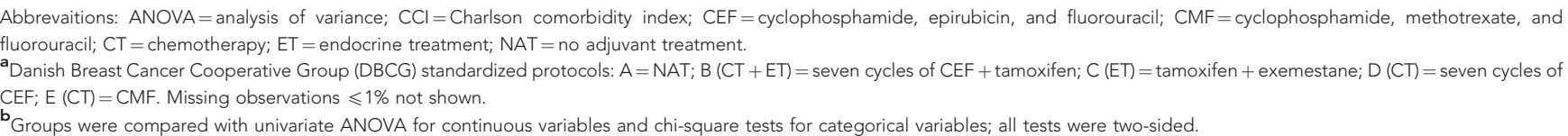 } \\
\hline
\end{tabular}


Table 3. Subjective Cognitive Impairment (CFQ ${ }^{a}$ total and factor scores) 7-9 years post surgery of women treated for primary breast cancer, presented by menopausal status and standard treatment protocols (A-E) for systemic therapy

\begin{tabular}{|c|c|c|c|c|c|}
\hline & \multicolumn{5}{|c|}{ Premenopausal at time of surgery, mean (s.d.; $n=751$ ) } \\
\hline Treatment Protocol ${ }^{b}$ & $\begin{array}{c}\mathrm{A}(-\mathrm{CT} /-\mathrm{ET}) \\
\operatorname{Mean}(\text { s.d.) }\end{array}$ & $\begin{array}{c}D(C T) \\
\text { Mean (s.d.) }\end{array}$ & $\begin{array}{l}\text { B (CT + ET) } \\
\text { Mean (s.d.) }\end{array}$ & $\begin{array}{c}\text { Unadjusted } A \text { vs } \\
\text { D/A vs } B \\
P \text {-value }\end{array}$ & $\begin{array}{c}\text { Fully adjusted }{ }^{c} A \text { vs } \\
\text { D/A vs B } \\
P \text {-value }\end{array}$ \\
\hline$N(\%)$ & $139(18.5)$ & $104(13.9)$ & $508(67.6)$ & & \\
\hline CFO total score & $32.4(12.8)$ & 34.4 (13.9) & $33.0(13.7)$ & $0.26 / 0.67$ & $0.32 / 0.66$ \\
\hline Forgetfulness & $13.3(4.9)$ & $14.2(5.5)$ & $13.6(5.4)$ & $0.17 / 0.50$ & $0.19 / 0.51$ \\
\hline Distractibility & $10.2(4.6)$ & $10.6(4.7)$ & $10.2(4.5)$ & $0.55 / 0.95$ & $0.60 / 0.89$ \\
\hline \multirow[t]{2}{*}{ False triggering } & $8.1(4.3)$ & $8.7(4.7)$ & $8.3(4.5)$ & $0.30 / 0.71$ & $0.44 / 0.85$ \\
\hline & \multicolumn{5}{|c|}{ Postmenopausal at time of surgery, mean (s.d.; $n=1138$ ) } \\
\hline Treatment Protocol ${ }^{b}$ & $\begin{array}{c}\mathrm{A}(-\mathrm{CT} /-\mathrm{ET}) \\
\text { Mean (s.d.) }\end{array}$ & $\begin{array}{c}E(C T) \\
\text { Mean (s.d.) }\end{array}$ & $\begin{array}{c}C(E T) \\
\text { Mean (s.d.) }\end{array}$ & $\begin{array}{c}\text { Unadjusted A vs } \\
\text { E/A vs C } \\
P \text {-value }\end{array}$ & $\begin{array}{c}\text { Fully adjusted }{ }^{\mathrm{c}} \mathrm{A} \text { vs } \\
\text { E/A vs C } \\
P \text {-value }\end{array}$ \\
\hline$N(\%)$ & $247(21.7)$ & $165(14.5)$ & $726(63.8)$ & & \\
\hline CFQ total score & $30.2(12.0)$ & $30.9(12.1)$ & 30.1 (11.9) & $0.55 / 0.93$ & $0.75 / 0.72$ \\
\hline Forgetfulness & $12.8(4.6)$ & $12.8(4.5)$ & $12.9(4.6)$ & $0.99 / 0.84$ & $0.91 / 0.95$ \\
\hline Distractibility & $9.1(4.2)$ & $9.1(4.0)$ & $9.0(4.0)$ & $0.92 / 0.85$ & $0.98 / 0.67$ \\
\hline False triggering & $7.3(3.8)$ & $7.6(3.7)$ & $7.4(3.9)$ & $0.51 / 0.86$ & $0.65 / 0.78$ \\
\hline \multicolumn{6}{|c|}{ 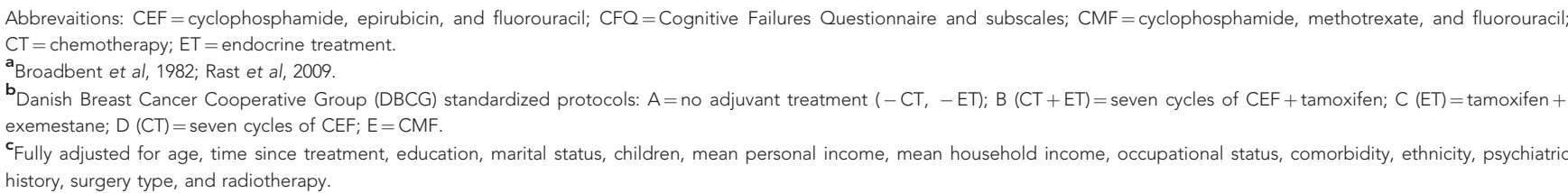 } \\
\hline
\end{tabular}

which the same criterion has been applied. For example, Ganz et al (2013) found that $20 \%$ of BC survivors reported significant SCI within 3 months from primary treatment. Our results may thus indicate that SCI gradually normalises over time. However, it should be noted that the average age of participants in that study was generally lower, and because younger age may be associated with more cognitive complaints, as reported in the present study, differences in the proportion of patients with significant SCI may be due to such age differences.

A recurrent finding regarding the relationship between objective and subjective measures of cognitive impairment is that these are not associated (Hermelink et al, 2010; Pullens et al, 2010; Hutchinson et al, 2012). Although there is emerging evidence to show that SCI in cancer patients may be related to both neuropsychological outcomes (Ganz et al, 2013, 2014) and to altered functional, morphological, and electrophysiological brain properties (Deprez et al, 2011, 2014; McDonald and Saykin, 2013; Hunter et al, 2014), SCI appears to be more strongly associated with psychological distress, for example, symptoms of depression and anxiety (Van Dam et al, 1998; Jenkins et al, 2006; Pullens et al, 2013). However, even if SCI was not, altogether, related to objective impairment, it inarguably remains an equally important research area in psychosocial cancer research, due to the well-known association between SCI and survivors' quality of life (Boykoff et al, 2009; Calvio et al, 2010; Wu et al, 2011; Von et al, 2013).

The present study adds to the literature in several ways. First, to our knowledge, it is the largest study investigating the long-term ( $>5$ years) effects of systemic therapy on SCI in BC survivors so far. Second, the study is based on data from a nationwide cohort, which adds considerably to the generalisability of the results. In addition, it is the first study to investigate the association between SCI and the allocation to standard treatment protocols for systemic therapy. Because of the large sample size, we were able to evaluate independent, as well as, combined effects of adjuvant treatments administered according to standard national guidelines. Comparing treatment protocols may offer a more valid approach to the investigation of SCI with results being more generalisable and translatable to clinical practice. As differential comparisons require large samples with adequate statistical power to detect betweengroup differences, it remains a challenge in most studies (Buwalda and Schagen, 2013). A further strength relates to the stratification by menopausal status in the statistical analyses. Menopausal status, and thereby age, influences the choice of adjuvant treatment and protocol allocation. Because age was related to SCI, this could introduce a potential confounding effect of age. An observed effect could thus be an age-related effect rather than an independent effect of systemic treatment per se. Other strengths include detailed data on relevant clinical variables as well as pre-cancer sociodemographic variables on all eligible women utilising the unique Danish population registries. This enabled us to adjust for multiple potential socioeconomic confounders and to perform reliable nonresponder analysis, which did not indicate any selection bias related to the treatment exposure (CT and/or ET).

Some limitations should also be noted. Despite the prospective nature of the present study, the CFQ was only administered at 7-9 years follow-up, which did not allow us to explore the course of SCI over time. Furthermore, it prevented us from exploring the possibility of attrition bias related to the initial level of SCI. At the 3-month follow-up, responders were, on average, younger than non-responders (See Christensen et al, 2009 for full details), which, given the observed negative association between age and SCI, may potentially pose a risk of an overestimation of SCI. Finally, because CFQ normative data were not available for the whole age-span, significant SCI was only determined for a subsample (36\%) of the cohort in the age range 63 to 74 years.

In conclusion, our results failed to confirm the hypothesis that women treated with systemic therapy experience long-term SCI when assessed 7-9 years post surgery. Furthermore, the observed 
proportion of survivors with significant SCI in the subgroup analysis was comparable to population norms. These results are important to communicate to patients, survivors, and clinicians alike, especially in the light of the increasing level of concern about cognitive impairment following systemic therapies.

\section{ACKNOWLEDGEMENTS}

We thank the participating women, the Danish Breast Cancer Cooperative Group (DBCG), Rigshospitalet, Copenhagen University Hospital, for providing the clinical data. This research was supported by The Danish Cancer Society (PP00014, PP03034), IMK Almene Fond (30206-215) and The Aase and Ejner Danielsen Foundation (106318).

\section{CONFLICT OF INTEREST}

The authors declare no conflict of interest.

\section{REFERENCES}

Ahn SH, Park BW, Noh DY, Nam SJ, Lee ES, Lee MK, Kim SH, Lee KM, Park SM, Yun YH (2007) Health-related quality of life in disease-free survivors of breast cancer with the general population. Ann Oncol 18: 173-182.

Bender CM, Sereika SM, Berga SL, Vogel VG, Brufsky AM, Paraska KK, Ryan CM (2006) Cognitive impairment associated with adjuvant therapy in breast cancer. Psychooncology 15: 422-430.

Boykoff N, Moieni M, Subramanian SK (2009) Confronting chemobrain: an in-depth look at survivors' reports of impact on work, social networks, and health care response. J Cancer Surviv 3: 223-232.

Bridger RS, Johnsen SÅK, Brasher K (2013) Psychometric properties of the Cognitive Failures Questionnaire. Ergonomics 56: 1515-1524.

Broadbent DE, Cooper PF, FitzGerald P, Parkes KR (1982) The Cognitive Failures Questionnaire (CFQ) and its correlates. Br J Clin Psychol 21(Pt 1): $1-16$.

Buwalda B, Schagen SB (2013) Is basic research providing answers if adjuvant anti-estrogen treatment of breast cancer can induce cognitive impairment? Life Sci 93: 581-588.

Calvio L, Peugeot M, Bruns GL, Todd BL, Feuerstein M (2010) Measures of cognitive function and work in occupationally active breast cancer survivors. J Occup Environ Med 52: 219-227.

Charlson ME, Pompei P, Ales KL, MacKenzie CR (1987) A new method of classifying prognostic comorbidity in longitudinal studies: development and validation. J Chronic Dis 40: 373-383.

Christensen S, Zachariae R, Jensen AB, Vaeth M, Møller S, Ravnsbaek J, von der Maase H (2009) Prevalence and risk of depressive symptoms 3-4 months post-surgery in a nationwide cohort study of Danish women treated for early stage breast-cancer. Breast Cancer Res Treat 113: 339-355.

Dalton SO, Düring M, Ross L, Carlsen K, Mortensen PB, Lynch J, Johansen C (2006) The relation between socioeconomic and demographic factors and tumour stage in women diagnosed with breast cancer in Denmark, 1983-1999. Br J Cancer 95: 653-659.

Deprez S, Amant F, Yigit R, Porke K, Verhoeven J, Van den Stock J, Smeets A, Christiaens M-R, Leemans A, Van Hecke W, Vandenberghe J, Vandenbulcke M, Sunaert S (2011) Chemotherapy-induced structural changes in cerebral white matter and its correlation with impaired cognitive functioning in breast cancer patients. Hum Brain Mapp 32: 480-493.

Deprez S, Vandenbulcke M, Peeters R, Emsell L, Smeets A, Christiaens M-R, Amant F, Sunaert S (2014) Longitudinal assessment of chemotherapyinduced alterations in brain activation during multitasking and its relation with cognitive complaints. J Clin Oncol 32: 2031-2038.

Ganz PA, Kwan L, Castellon SA, Oppenheim A, Bower JE, Silverman DHS, Cole SW, Irwin MR, Ancoli-Israel S, Belin TR (2013) Cognitive complaints after breast cancer treatments: examining the relationship with neuropsychological test performance. J Natl Cancer Inst 105: 791-801.

Ganz PA, Petersen L, Castellon SA, Bower JE, Silverman DHS, Cole SW, Irwin MR, Belin TR (2014) Cognitive function after the initiation of adjuvant endocrine therapy in early-stage breast cancer: an observational cohort study. J Clin Oncol 32: 3559-3567.

Gjerstorff ML (2011) The Danish Cancer Registry. Scand J Public Health 39: $42-45$.

Hermelink K, Küchenhoff $H$, Untch M, Bauerfeind I, Lux MP, Bühner M, Manitz J, Fensterer V, Münzel K (2010) Two different sides of 'chemobrain': determinants and nondeterminants of self-perceived cognitive dysfunction in a prospective, randomized, multicenter study. Psychooncology 19: 1321-1328.

Hunter AM, Kwan L, Ercoli LM, Mills BK, Cook IA, Ganz PA, Leuchter AF (2014) Quantitative electroencephalography biomarkers of cognitive complaints after adjuvant therapy in breast cancer survivors: a pilot study. Psychooncology 23: 713-715.

Hutchinson AD, Hosking JR, Kichenadasse G, Mattiske JK, Wilson C (2012) Objective and subjective cognitive impairment following chemotherapy for cancer: a systematic review. Cancer Treat Rev 38: 926-934.

Jenkins V, Shilling V, Deutsch G, Bloomfield D, Morris R, Allan S, Bishop H, Hodson N, Mitra S, Sadler G, Shah E, Stein R, Whitehead S, Winstanley J (2006) A 3-year prospective study of the effects of adjuvant treatments on cognition in women with early stage breast cancer. Br J Cancer $\mathbf{9 4}$ : 828-834.

Jenkins VA, Ambroisine LM, Atkins L, Cuzick J, Howell A, Fallowfield LJ (2008) Effects of anastrozole on cognitive performance in postmenopausal women: a randomised, double-blind chemoprevention trial (IBIS II). Lancet Oncol 9: 953-961.

Kilickap S, Hayran M, Cakir B, Cilingiroglu N, Erman M, Buyukdamgaci G, Ozisik Y (2013) Effect of endocrine therapy on quality of life and cognitive functions in patients with breast cancer. Breast Care (Basel) 8: 128-132.

Knight RG, McMahon J, Green TJ, Skeaff CM (2004) Some Normative and Psychometric Data for the Geriatric Depression Scale and the Cognitive Failures Questionnaire from a sample of healthy older persons. NZ J Psychol 33: 163.

Koppelmans V, Breteler MMB, Boogerd W, Seynaeve C, Schagen SB (2013) Late effects of adjuvant chemotherapy for adult onset non-CNS cancer; cognitive impairment, brain structure and risk of dementia. Crit Rev Oncol Hematol 88: 87-101.

McDonald BC, Saykin AJ (2013) Alterations in brain structure related to breast cancer and its treatment: chemotherapy and other considerations. Brain Imaging Behav 7(4): 374-387.

McEwen BS, Alves SE (1999) Estrogen actions in the central nervous system. Endocr Rev 20: 279-307.

Mehlsen M, Pedersen AD, Jensen AB, Zachariae R (2009) No indications of cognitive side-effects in a prospective study of breast cancer patients receiving adjuvant chemotherapy. Psychooncology 18: 248-257.

O'Connor M, Christensen S, Jensen AB, Møller S, Zachariae R (2011) How traumatic is breast cancer? Post-traumatic stress symptoms (PTSS) and risk factors for severe PTSS at 3 and 15 months after surgery in a nationwide cohort of Danish women treated for primary breast cancer. $\mathrm{Br}$ J Cancer 104: 419-426.

OECD Better Life Index (2014) http://www.oecdbetterlifeindex.org.

Pullens MJJ, De Vries J, Roukema JA (2010) Subjective cognitive dysfunction in breast cancer patients: a systematic review. Psychooncology 19: $1127-1138$.

Pullens MJJ, De Vries J, Van Warmerdam LJC, Van De Wal MA, Roukema JA (2013) Chemotherapy and cognitive complaints in women with breast cancer. Psychooncology 22: 1783-1789.

Rast P, Zimprich D, Van Boxtel M, Jolles J (2009) Factor structure and measurement invariance of the cognitive failures questionnaire across the adult life span. Assessment 16: 145-158.

Reid-Arndt SA, Hsieh C, Perry MC (2010) Neuropsychological functioning and quality of life during the first year after completing chemotherapy for breast cancer. Psychooncology 19: 535-544.

Ribi K, Aldridge J, Phillips K-A, Thompson A, Harvey V, Thürlimann B, Cardoso F, Pagani O, Coates AS, Goldhirsch A, Price KN, Gelber RD, Bernhard J (2012) Subjective cognitive complaints one year after ceasing adjuvant endocrine treatment for early-stage breast cancer. $\mathrm{Br} J$ Cancer 106: $1618-1625$.

Rostgaard K, Holst H, Mouridsen HT, Lynge E (2000) Do clinical databases render population-based cancer registers obsolete? The example of breast cancer in Denmark. Cancer Causes Control 11: 669-674.

Schilder CMT, Seynaeve C, Linn SC, Boogerd W, LVAM Beex, Gundy CM, Nortier JWR, van de Velde CJH, van Dam FSAM, Schagen SB (2012) Self-reported cognitive functioning in postmenopausal breast cancer 
patients before and during endocrine treatment: findings from the neuropsychological TEAM side-study. Psychooncology 21: 479-487.

Shilling V, Jenkins V (2007) Self-reported cognitive problems in women receiving adjuvant therapy for breast cancer. Eur J Oncol Nurs 11: 6-15.

Singletary SE, Allred C, Ashley P, Bassett LW, Berry D, Bland KI, Borgen PI, Clark G, Edge SB, Hayes DF, Hughes LL, Hutter RVP, Morrow M, Page DL, Recht A, Theriault RL, Thor A, Weaver DL, Wieand HS, Greene FL (2002) Revision of the American Joint Committee on Cancer staging system for breast cancer. J Clin Oncol 20: 3628-3636.

Sullivan Mitchell E, Fugate Woods N (2001) Midlife women's attributions about perceived memory changes: observations from the Seattle Midlife Women's Health Study. J Womens Health Gend Based Med 10: 351-362.

Thygesen LC, Daasnes C, Thaulow I, Brønnum-Hansen H (2011) Introduction to Danish (nationwide) registers on health and social issues: structure, access, legislation, and archiving. Scand J Public Health 39: $12-16$.

Vandenbroucke JP, von Elm E, Altman DG, Gøtzsche PC, Mulrow CD, Pocock SJ, Poole C, Schlesselman JJ, Egger M (2014) Strengthening the Reporting of Observational Studies in Epidemiology (STROBE): explanation and elaboration. Int J Surg 12: 1500-1524.

Van Londen GJ, Beckjord EB, Dew MA, Cooper KL, Davidson NE, Bovbjerg DH, Donovan HS, Thurston RC, Morse JQ, Nutt S, Rechis R (2014) Associations between adjuvant endocrine therapy and onset of physical and emotional concerns among breast cancer survivors. Support Care Cancer 22: 937-945.

Van Dam FS, Schagen SB, Muller MJ, Boogerd W, vd Wall E, Droogleever Fortuyn ME, Rodenhuis S (1998) Impairment of cognitive function in women receiving adjuvant treatment for high-risk breast cancer: high-dose versus standard-dose chemotherapy. J Natl Cancer Inst 90: 210-218.

Von Ah D, Carpenter JS, Saykin A, Monahan P, Wu J, Yu M, Rebok G, Ball K, Schneider B, Weaver M, Tallman E, Unverzagt F (2012) Advanced cognitive training for breast cancer survivors: a randomized controlled trial. Breast Cancer Res Treat 135: 799-809.

Von AD, Habermann B, Carpenter JS, Schneider BL (2013) Impact of perceived cognitive impairment in breast cancer survivors. Eur J Oncol Nurs 17: 236-241.

Weber MT, Maki PM, McDermott MP (2013) Cognition and mood in perimenopause: a systematic review and meta-analysis. J Steroid Biochem Mol Biol 142: 90-98.

Wu LM, Austin J, Hamilton JG, Valdimarsdottir H, Isola L, Rowley S, Warbet R, Winkel G, Redd WH, Rini C (2011) Self-efficacy beliefs mediate the relationship between subjective cognitive functioning and physical and mental well-being after hematopoietic stem cell transplant. Psychooncology 21(11): 1175-1184.

Yamada TH, Denburg NL, Beglinger LJ, Schultz SK (2010) Neuropsychological outcomes of older breast cancer survivors: cognitive features ten or more years after chemotherapy. J Neuropsychiatry Clin Neurosci 22: $48-54$.

This work is published under the standard license to publish agreement. After 12 months the work will become freely available and the license terms will switch to a Creative Commons AttributionNonCommercial-Share Alike 4.0 Unported License 